\title{
Passive sinking into the snow as possible survival strategy during the off-host stage in an insect ectoparasite
}

\author{
Sirpa Kaunisto ${ }^{1}$, Hannu Ylönen ${ }^{2}$ and Raine Kortet $^{1}$ \\ ${ }^{1}$ University of Eastern Finland, Department of Biology, Joensuu, Finland; \\ ${ }^{2}$ University of Jyväskylä, Department of Biological and Environmental Science, Konnevesi Research Station, Jyväskylä, Finland
}

\begin{abstract}
Abiotic and biotic factors determine success or failure of individual organisms, populations and species. The early life stages are often the most vulnerable to heavy mortality due to environmental conditions. The deer ked (Lipoptena cervi Linnaeus, 1758) is an invasive insect ectoparasite of cervids that spends an important period of the life cycle outside host as immobile pupa. During winter, dark-coloured pupae drop off the host onto the snow, where they are exposed to environmental temperature variation and predation as long as the new snowfall provides shelter against these mortality factors. The other possible option is to passively sink into the snow, which is aided by morphology of pupae. Here, we experimentally studied passive snow sinking capacity of pupae of $L$. cervi. We show that pupae have a notable passive snow sinking capacity, which is the most likely explained by pupal morphology enabling solar energy absorption and pupal weight. The present results can be used when planning future studies and when evaluating possible predation risk and overall survival of this invasive ectoparasite species in changing environmental conditions.
\end{abstract}

Keywords: ectoparasite, Hippoboscidae, invasive species, Cervidae, low temperature, morphology, predation, pupa

Abiotic and biotic factors determine the success or failure of individual organisms, populations and species. Environmental factors (e.g. solar radiation, temperature, moisture) and biotic relationships (e.g. predation, parasitism, competition) shape the structure and function of organisms through evolutionary time scale (Fox et al. 2001). Organisms, including parasitic insects, have adapted their traits in response to changes in their environment. Insect species show diverse morphological, behavioural and physiological adaptations to their environment (Bernays et al. 1991, Gullan and Kosztarab 1997, Eberhard 2001, Chown and Nicolson 2004, Capinera 2008).

These adaptations make insects the most successful and abundant animals having large ecological and socioeconomic impacts as pollinators, nutrient cyclers, crop and forest pests, mammalian ectoparasites, and as disease vectors (Murdock et al. 2013, Prather et al. 2013, Korhonen et al. 2014). Both the active and resting life stages of insects and insect ectoparasites require traits that could protect them against harsh climatic factors (e.g. low/high temperature, dryness), or predators and pathogens (Tauber et al. 1986, Capinera 2008, Härkönen et al. 2012, Kaunisto et al. 2012, Nieminen et al. 2012). Especially the earliest life stages are often the most vulnerable experiencing heavy mortality due to environmental and biotic regulators (Gullan and Cranston 2010).
Towards the northern boreal environment winters become colder followed by longer-lasting snow cover (Tauber et al. 1986). Low temperature extremes in winter are among the most important environmental constraints for insect distribution and activity patterns (Gaston 2003, Denlinger and Lee 2010). Temperature affects most physiological processes and has a strong influence on the development, growth, reproduction and survival of insects (Bale et al. 2002, Régnière et al. 2012). During winter, snow cover plays a major role for survival of many insects providing thermal insulation as well as shelter from winteractive predators (Aitchison 2001, Hågvar 2010). Although most Fennoscandian terrestrial arthropods pass the winter in an inactive state, the capability of immobilised insect life-stages to get access and survive within the refuge surrounded by snow is poorly known. The immobilised passive stages are vulnerable for environmental variation and predation, because they cannot actively seek shelter if the fluctuating freeze and thaw periods cause snow cover to diminish. Therefore, morphological traits (e.g. shape, structure, colour) of immobilised stages can potentially provide camouflage against predation but also help get access to thermal refuge under/within snow.

Our study species, the deer ked, Lipoptena cervi Linnaeus, 1758 (Diptera: Hippoboscidae), is a blood-feeding insect ectoparasite of various boreal cervids. Lipoptena

Address for correspondence: S. Kaunisto, University of Eastern Finland, Department of Biology, P.O. Box 111, FI-80101 Joensuu, Finland. Phone: + 358504904831 ; Fax: +358 13318 039; E-mail: sirpa.kaunisto@uef.fi 


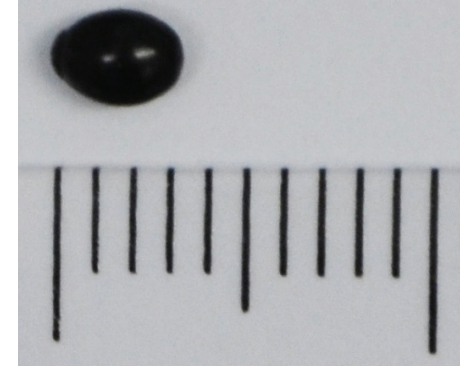

Fig. 1 Pupal stage of Lipoptena cervi Linnaeus, 1758.

cervi has expanded its range in the Palaearctic region, but it has also been introduced to the Nearctic region (e.g. Välimäki et al. 2010, Samuel et al. 2012). Adult L. cervi may cause negative effects on cervid hosts and on accidental hosts such as humans (Reunala et al. 2008, Madslien et al. 2011, Kynkäänniemi et al. 2014). Pupal and adult stage are also known to carry haemotrophic bacteria (Bartonella spp.) infecting ruminants (Dehio et al. 2004, Duodu et al. 2013, Korhonen et al. 2014).

Lipoptena cervi lives on a cervid host as adults (eggs and larval stages occurring within the female's reproductive tract), but the immobile pupal stage occurs without host (Fig. 1). Pupae drop of the host onto the ground, ice or snow soon after birth (Haarløv 1964, Härkönen et al. 2013). Female's reproductive output is being dispersed evenly across the whole reproductive phase, which lasts from autumn to the following spring. Therefore, duration of the off-host pupal stage may last up to ten months depending on birth time of a pupa (Haarløv 1964, Härkönen et al. 2012). Pupae encounter different seasonal environments in autumn, winter and spring, while pupal development (i.e. adult metamorphosis) occurs during summer and host searching of newly emerged adults takes place in early autumn. It has been reported that overwintering and diapausing $L$. cervi pupae can survive only 3-4 days of harsh frosts $\left(-15^{\circ} \mathrm{C}\right.$ to $\left.-20^{\circ} \mathrm{C}\right)$ without insulating snow cover (Härkönen et al. 2012).

Complete pupae of $L$. cervi are deep black, oval- or almost round-shaped and approximately $3 \mathrm{~mm}$ in diameter. Black pupae were previously shown to be exposed to high predation risk by avian predators against snow on cervid bedding sites (Kaunisto et al. 2012). Therefore, one would predict that $L$. cervi pupae have evolved to sink deeper into the snow as soon as possible in order to hide from predators but also to have access to shelter from extreme coldness on the snow surface.

Although there are increasing data on physiological/biochemical adjustments of diapausing pupae and other insect life stages for winter (e.g. removing ice nucleating agents from body fluids), it is not known how morphology per se improves overwintering survival. In the present study, we investigated in the field conditions whether morphology of immobilised pupal stage of $L$. cervi could help pupae passively sink deeper into snow. We studied whether pupae can utilise daylight in penetrating deeper into snow (likely by absorbing solar radiation to heat their way through snow). We also explored whether the weight of pupa af- fects passive sinking speed into snow. We predicted that both the exposure to uncovered daylight and pupal weight would affect pupal capacity to sink into the snow. Passive gravity- and solar-aided sinking into snow, if observed, can potentially help pupae in escaping low temperatures and predation, and gives reason for further studies.

\section{MATERIALS AND METHODS}

\section{Pupal collection and measurements}

For the experiments we collected pupae of Lipoptena cervi from winter bedding sites of moose (Alces alces Linnaeus) in the commune of Siikalatva, northern central Finland $\left(64^{\circ} 16^{\prime} \mathrm{N}\right.$; $25^{\circ} 52^{\prime} \mathrm{E}$ ), on 18 March 2010 . Forty eight hours after the collection, pupal mass was measured with a micro balance (Sartorius - 4503 MP6E Microbalance, accuracy of $0.001 \mathrm{mg}$ ). The width of the pupae was measured under a stereomicroscope with scale markings. Before the experiments, we carefully inspected the condition of pupae under a stereomicroscope and only alive pupae with intact pupal shell were used in the experiments. The colouration of pupae did not vary when estimated ocularly under different light conditions. Until the field experiments, all pupae were kept in a cold room $\left(+3^{\circ} \mathrm{C}\right)$ to mimic subnival temperature conditions in nature. Field experiments took place within a week after the collection.

\section{Experimental field setup}

The experiment was conducted in an open field in Joensuu, Penttilänranta $\left(62^{\circ} 59^{\prime} \mathrm{N}\right.$; $\left.29^{\circ} 75^{\prime} \mathrm{E}\right)$, eastern Finland. The experiment was carried out between 23-24 March 2010. To study the capacity of diapausing immobilised pupae of $L$. cervi to passively bury into the snow, we had one experiment with two treatments. In the first treatment, we put 14 pupae of $L$. cervi carefully sideways onto undisturbed snow in a same position (without causing any human-related physical pressure on the snow), and exposed the pupae directly to occurring weather conditions for 32 hours. The second treatment was similar, but we also constructed a parasol for each individual pupa $(n=14)$ placed onto the snow cover for 32 hours. The first treatment was mimicking the situation on field or clearcut habitats, where especially the latter represents a preferred bedding habitat of the moose in shady areas. In the second treatment, the parasol blocked direct sunlight and mimicked conditions of shady forest keeping otherwise the habitat and snow properties similar to the first treatment. The parasols were made of a folded, C4-size envelope $(229 \times 324 \mathrm{~mm}$, gray $)$, which was attached into snow cover with four six inch nails (one in each corner). The parasol enabled air currents to surround pupa. In the both treatments the snow cover was relatively hard after consecutive thaw and freeze periods. The sample size (14 pupae per treatment) was selected for practical reasons and was relatively easily observable.

The experiment started at 9:00 AM on 23 March and ended the following day at 5:00 PM. During the 32-hour experiment, the weather represented normal winter conditions in Finland; the highest temperature observed was $+1{ }^{\circ} \mathrm{C}$ (at 3:00 PM, 24 March) and lowest temperature was observed at night $-14^{\circ} \mathrm{C}$ (Finnish Meteorological Institute 2010). During the day times (12 AM-5 PM), the temperatures were just below $0^{\circ} \mathrm{C}$. On both of the mornings and the evening, temperatures were clearly below zero. Both of 


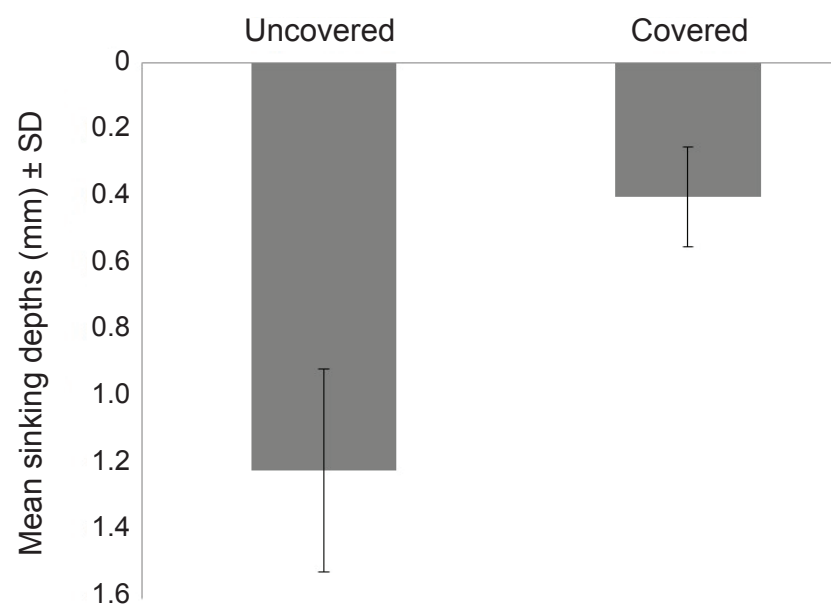

Fig. 2 Mean sinking depths $(\mathrm{mm}) \pm \mathrm{SD}$ of the pupae in the two treatments of the field experiment: uncovered (daylight) and covered (shadow) snow areas.

the experimental days were sunny, only partial cloudiness was observed for couple of hours in the second day. There was no snowfall. During the first day, there was a relatively strong, gusty wind coming from the northwest. Next day, the wind died down a lot and there was only a weak wind coming from the northwest.

At the end of the experiment, we studied possible predation loss of pupae and measured how large portion of the pupae was in sight above the snow cover by using a Cocraft Digital caliper (accuracy $0.01 \mathrm{~mm}$ ). Then this measured value above snow level was subtracted from the total width value of the pupae to get information how much each pupa had sunk into the snow during the experiment.

\section{Statistical analyses}

The data were analysed with a software package used for statistical analysis for Windows (SPSS version 19.0, IBM) for Windows (version 19.0). We ran the analysis of covariance (ANCOVA) for the data. The level of significance (P-value) for the statistical analysis was set at $\mathrm{P}<0.05$. The dependent variable was set as the capacity of pupae to sink into the snow (mm). Treatment (uncovered/covered) was set as a fixed factor. The pupal weight $(\mathrm{mg})$ was treated as a covariate. All the assumptions required for the conduction of ANCOVA were met except for the assumption for homogeneity of variances. Since we did not have adequate homogeneity of variances, we conducted the logarithmic transformation $\left(\log _{10}\right)$ for the dependent variable, which resulted in homogeneity of variances (Levene's test; $\mathrm{P}=0.952$ ). Assumption of a linear relationship between the covariate and the dependent variable in both treatment groups was met. There was homogeneity of regression slopes as the interaction term was not statistically significant $\left(F_{1,24}=3.502, \mathrm{P}=0.074\right)$. Standardised residuals for the treatments and for the overall model were normally distributed, as assessed by Shapiro-Wilk's test $(\mathrm{P}>0.05)$. There were no outliers in the data.

\section{RESULTS}

None of the experimental pupae were predated, likely because the study site is located close to the urban area with no previous observations of the host animals and Lipoptena cervi. The mean pupal weight was $11.39 \mathrm{mg}$ (standard deviation $[\mathrm{SD}]=1.01$; standard error $[\mathrm{SE}]=0.19)$. The mean width of the pupae was $2.53 \mathrm{~mm}(\mathrm{SD}=0.076$; SE $=0.014$ ). When pupae were exposed to the uncovered daylight, on average $48 \%$ of the pupal total width had sunk into the snow $(\mathrm{SD}=12 ; \mathrm{SE}=3)$ at the end of the 32-hour field experiment. In contrast, in the shadow treatment, on average $16 \%$ of the pupal total width had sunk into the snow ( $\mathrm{SD}=5.68$; $\mathrm{SE}=1.52)$. After adjustment for the pupal weight in the ANCOVA model, treatment (uncovered/ covered) had a significant effect on the pupal capacity to passively bury into the snow $\left(F_{1,25}=96.94, \mathrm{P}<0.001\right)$. Pupae exposed directly to the daylight sank deeper into to the snow than pupae kept in the shadow (Fig. 2). In the model, also the pupal weight affected significantly the pupal capacity to sink into the snow $\left(F_{1,25}=9.035, \mathrm{P}=0.006\right)$. The relationship between the dependent variable (millimetres that pupa had sunk) and the independent variable (pupal weight) was a weakly positive linear $\left(R^{2}=0.06\right)$.

\section{DISCUSSION}

The present study was conducted in natural winter conditions to assess whether Lipoptena cervi pupae can passively penetrate deeper into snow and thereby possibly escape winter temperatures and predation which have previously shown to be important mortality factors for $L$. cervi pupae (see Härkönen et al. 2012, Kaunisto et al. 2012). Our present results show that higher pupal weight aided immobilised $L$. cervi pupae to sink deeper into the snow. In addition, pupal characteristics interact with daylight enabling pupae to passively penetrate deeper into snow. This present study provides first estimation of the capability of immobilised life-stages of insects and ectoparasites to passively sink in a refuge surrounded by snow.

Heavier pupae sink deeper into the snow more effectively, which is logical since the sinking is ultimately caused by the gravity. In other living and non-living objects, the weight and associated pressure affect the sinking depth (Parramón Studios 2004, Farnes 2008). The heavier the object is, the higher pressure applied to the snow surface radiates outward from the object and the sinking depth of the object gets deeper. However, it should be noted that the surface area of the object affects negatively the pressure and sinking depth. Therefore, the larger the surface area of the object, the weight is more evenly distributed and the pressure directed to the one point of snow surface is smaller. In our experiment, pupae of $L$. cervi were set onto the snow cover very carefully sideways in a same position to minimise the effects of variation in the surface area between individuals.

In general, also the snow composition and density affect the amount of pressure the snow cover can support and thus sinking depth of an object (Parramón Studios 2004, Farnes 2008). Objects sink deeper into light-density snow when the pressure is horizontally distributed, whereas the sinking depth is less in dense snow when the pressure is confined directly under the object. In our experiment, the snow cover was hard and dense after consecutive thaw and freeze periods. Despite the very hard snow cover in our experiment, pupae managed to sink deeper into snow already 
within 32 hours (almost $50 \%$ of the pupal surface had sunk into the snow when exposed direct daylight). Texture of the snow during this experiment was ideal because it resembled snow density on bedding sites of the endothermic hosts. Pupae of $L$. cervi are most commonly found on the bedding sites of cervids, and when the resting large-bodied cervids melt the snow underneath, the upper snow layer of the bedding site thus becoming very dense (Kaunisto et al. 2009). In our experiment, pupae were mostly exposed to below zero temperatures. It can be roughly estimated that in conditions resembling our experimental setting in the first treatment (i.e. hard snow cover, relatively low temperature, no new snowfall, direct daylight), L. cervi pupae are totally buried inside snow in ca 64 hours. It is possible that some of the pupae will drop onto light-density snow spots outside the bedding sites, or some of the bedding sites are not so compacted depending on the body weight of the host. Based on our personal observations, during the warm, sunny thawing days with more light-density snow L. cervi pupae sink more quickly deeper into the snow. However, further research on the relationships between snow texture, weather conditions (e.g. temperatures) and pupal sinking capacity are needed in order to make more far-reaching conclusions.

Our results show that pupae of $L$. cervi exposed directly to the daylight sank deeper into the snow than pupae kept in the shadow. Therefore, it seems that some of the pupal characteristics interact with direct daylight enabling pupae to passively penetrate deeper into the snow. It is possible that the deep-black cuticle colour of pupae absorbed more effectively direct daylight than light that was blocked by the parasol. In general, solid black objects absorb all sunlight (albedo of zero) and the absorbed light gets converted to other forms of energy, usually heat, which is then emitted by the object (Siegel and Howell 2002). Therefore, black pupae likely converted direct daylight to greater amount of heat and heated their way deeper into the snow. Further and more specific studies on the role of black pupal colour in the passive burying into snow are needed. Future studies could also help understand possible benefits and disadvantages of black pupal colour in L. cervi. Dark surface colouration may for example represent an adaptive thermoregulatory trait if the dark colouration enables to better absorb short-wave solar radiation and thus attain higher body temperature during cold times and also aid snow burying capacity (Harrison et al. 2012).

To conclude, pupae exposed to the direct daylight sank deeper into the snow, indicating that solar energy may play a role in winter ecology of $L$. cervi. As pupae are shown to stand very cold temperatures for couple of days (Härkönen et al. 2012), the main thermal benefit in being surrounded by the snow may be the avoidance of strong diel temperature fluctuations and long-lasting high-pressure periods. Passive burying into the snow may also provide escaping from visually hunting predators like titmice (Kaunisto et al. 2012). Even small magnitude differences in passive snow burying capacity can have ecological significance in conditions where the new snowfalls are unpredictably. Further studies need to be conducted on the effects of different snow textures and weather conditions (e.g. temperatures, light intensities) on pupal sinking capacity and pupal predation rate.

Acknowledgements. We thank anonymous referees for the comments on the previous version of the manuscript. We also thank Hilkka and Lauri Kortet for their help with the pupal collection. This study was partly funded by several foundations: the Ella and Georg Ehrnrooth Foundation, the Biological Society of Finland Vanamo, Societas Pro Fauna et Flora Fennica, and the Alfred Kordelin Foundation. We conducted this study in accordance with the Finnish legislation.

\section{REFERENCES}

Aitchison C.W. 2001: The effect of snow cover on small animals. In: H.G. Jones, J.W. Pomeroy, D.A. Walker and R.W. Hoham (Eds.), Snow Ecology: an Interdisciplinary Examination of Snow-Covered Ecosystems. Cambridge University Press, Cambridge, pp. 229-265.

Bale J.S., Masters G.J., Hodkinson I.D., Awmack C., Bezemer T.M., Brown V.K., Butterfield J., Buse A., Coulson J.C., Farrar J., Good J.E.G., Harrington R., Hartley S., Jones T.H., Lindroth R.L., Press M.C., Symrnioudis I., Watt A.D., Whittaker J.B. 2002: Herbivory in global climate change research: direct effects of rising temperature on insect herbivores. Glob. Change Biol. 8: 1-16.

Bernays E.A., Jarzembowski E.A., Malcolm S.B. 1991: Evolution of insect morphology in relation to plants. Philos. Trans. R. Soc. Lond. B 333: 257-264.

Capinera J.L. (Ed.) 2008: Encyclopedia of Entomology. Second Edition. Springer Science + Business Media B.V., Dordrecht, $4346 \mathrm{pp}$.

Chown S.L., Nicolson S.W. 2004: Insect Physiological Ecology: Mechanisms and Patterns. Oxford University Press Inc., New York, 254 pp.

Dehio C., Sauder U., Hiestand R. 2004: Isolation of Bartonella schoenbuchensis from Lipoptena cervi, a blood-sucking arthro- pod causing deer ked dermatitis. J. Clin. Microbiol. 42: 53205323.

Denlinger D.L., Lee R.E. (Eds.) 2010: Low Temperature Biology of Insects. Cambridge University Press, Cambridge, 390 pp.

Duodu S., Madslien K., Huelm E., Molin Y., PaziewskaHarris A., Harris P.D., Colquhoun D.J., Ytrehus B. 2013: Bartonella infections in deer keds (Lipoptena cervi) and moose (Alces alces) in Norway. Appl. Environ. Microbiol. 79: $322-327$.

EBERHARD W.G. 2001: The functional morphology of species-specific clasping structures on the front legs of male Archisepsis and Palaeosepsis flies (Diptera, Sepsidae). Zool. J. Linn. Soc. 133: 335-368.

FARnes P.E. 2008: Snow sinking studies. Proceedings of the $76^{\text {th }}$ Annual Western Snow Conference. Hood River, Oregon, 14-17 April 2008, pp. 3-10.

Finnish Meteorological Institute 2010: http:// en.ilmatieteenlaitos.fi/., 03/2010.

Fox C.W., Roff D.A., FAIrbairn D.J. (Eds.) 2001: Evolutionary Ecology: Concepts and Case Studies. Oxford University Press, Inc., New York, 448 pp.

Gaston K.J. 2003: The Structure and Dynamics of Geographic Ranges. Oxford University Press, New York, 278 pp. 
Gullan P.J., Cranston P.S. 2010: The Insects: an Outline of Entomology, Fourth Edition. Wiley-Blackwell Science, West Sussex, $584 \mathrm{pp}$.

Gullan P.J., Kosztarab M. 1997: Adaptations in scale insects. Annu. Rev. Entomol. 42: 23-50.

HAARLøv N. 1964: Life cycle and distribution pattern of Lipoptena cervi (L.) (Dipt., Hippobosc.) on Danish deer. Oikos 15: 93-129.

HÅGVAR S. 2010: A review of Fennoscandian arthropods living on and in snow. Eur. J. Entomol. 107: 281-298.

Härkönen L., Hurme E., Kaitala A. 2013: Unexpected seasonal variation in offspring size and performance in a viviparous ectoparasite. Parasitology 140: 229-236.

Härkönen L., Kaitala A., Kaunisto S., Repo T. 2012: High cold tolerance through four seasons and all free-living stages in an ectoparasite. Parasitology 139: 926-933.

Harrison J.F., Woods H.A., Roberts S.P. 2012: Ecological and Environmental Physiology of Insects. Oxford University Press Inc., New York, 372 pp.

Kaunisto S., Kortet R., Härkönen L., Härkönen S., YlöneN H., LAAKSONEN S. 2009: New bedding site examination-based method to analyse deer ked (Lipoptena cervi) infection in cervids. Parasitol. Res. 104: 919-925.

Kaunisto S., Välimäki P., Kortet R., Koskimäki J., HärkÖNen S., Kaitala A., LaAKsonen S., Härkönen L., YLÖNEN H. 2012: Avian predation on a parasitic fly of cervids during winter: can host-related cues increase the predation risk? Biol. J. Linnean Soc. 106: 275-286.

Korhonen E.M., Pérez-Vera C., Pulliainen A.T., Sironen T., Aaltonen K., Kortet R., Härkönen L., Härkönen S., Paakkonen T., Nieminen P., Mustonen A.M., Ylönen H., Vapalahti O. 2014: Molecular detection of Bartonella spp. in deer ked pupae, adult keds and moose blood in Finland. Epidemiol. Infect. 5: 1-8.

KynkäÄnniemi S.M., Kettu M., Kortet R., Härkönen L., Kaitala A., Paakkonen T., Mustonen A.M., Nieminen P., Härkönen S., Ylönen H., LaAksonen S. 2014: Acute impacts of the deer ked (Lipoptena cervi) infestation on reindeer (Rangifer tarandus tarandus) behaviour. Parasitol. Res. 113: 1489-1497.

Received 20 February 2015

Accepted 22 April 2015
Madslien K., Ytrehus B., Vikøren T., Malmsten J., IsaKSen K., Hygen H.O., Solberg E.J. 2011: Hair-loss epizootic in moose (Alces alces) associated with massive deer ked (Lipoptena cervi) infestation. J. Wildl. Dis. 47: 893-906.

Murdock C.C., Moller-Jacobs L.L., Thomas M.B. 2013: Complex environmental drivers of immunity and resistance in malaria mosquitoes. Proc. R. Soc. B 280: 2013-2030.

Nieminen P., Paakkonen T., Eerilä H., Puukka K., Riikonen J., Lehto V.P., Mustonen A.M. 2012: Freezing tolerance and low molecular weight cryoprotectants in an invasive parasitic fly, the deer ked (Lipoptena cervi). J. Exp. Zool. A 317: 1-8.

PArRamón Studios (Ed.) 2004: Essential Atlas of Physics and Chemistry. Barrons Educational Series, Inc., New York, 96 pp.

Prather C.M., Pelini S.L., Laws A., Rivest E., Woltz M., Bloch C.P., Del Toro I., Ho C.K., Kominoski J., Newbold T.A., Parsons S., Joern A. 2013: Invertebrates, ecosystem services and climate change. Biol. Rev. Camb. Philos. Soc. 88: $327-348$.

Régnière J., Powell J., Bentz B., Nealis V. 2012: Effects of temperature on development, survival and reproduction of insects: experimental design, data analysis and modeling. J. Insect Physiol. 58: 634-647.

Reunala T., Laine M., Vornanen M., Härkönen S. 2008: Hirvikärpäsihottuma: maanlaajuinen riesa [The deer ked dermatitis: a nationwide problem]. Duodecim 124: 1607-1613. (In Finnish.)

Samuel W.M., Madslien K., Gonynor-McGuire J. 2012: Review of deer ked (Lipoptena cervi) on moose in Scandinavia with implications for North America. Alces 48: 27-33.

Siegel R., Howell J. 2002: Thermal Radiation: Heat Transfer. Fourth Edition. Taylor \& Francis, New York, 869 pp.

Tauber M.J., Tauber C.A., Mazaki S. 1986: Seasonal Adaptations of Insects. Oxford University Press Inc., New York, 412 pp.

VÄlimäki P., Madslien K., Malmsten J., Härkönen L., Härkönen S., Kaitala A., Kortet R., LaAksonen S., Mehl R., Redford L., Ylönen H., Ytrehus B. 2010: Fennoscandian distribution of an important parasite of cervids, the deer ked (Lipoptena cervi), revisited. Parasitol. Res. 107: 117125 .

Cite this article as: Kaunisto S., Ylönen H., Kortet R. 2015: Passive sinking into the snow as possible survival strategy during the off-host stage in an insect ectoparasite. Folia Parasitol. 62: 038. 